\title{
Nonalcoholic Fatty Liver Disease of Two Ethnic Groups in Kuwait: Comparison of Prevalence and Risk Factors
}

\author{
Pavel Babusik $^{a}$ Maha Bilal $^{b}$ Ivan Duris ${ }^{c}$ \\ Departments of ${ }^{\mathrm{a}}$ Internal Medicine and ${ }^{\mathrm{b}}$ Radiology, Al-Rashid Hospital, Salmiya, Kuwait; ${ }^{\mathrm{c}}$ Medical Faculty of \\ Comenius University, Bratislava, Slovakia
}

\section{Key Words}

Nonalcoholic liver steatosis - Arabic ethnicity · South Asian ethnicity - Obesity

\begin{abstract}
Objectives: To assess the prevalence of nonalcoholic hepatic steatosis (nonalcoholic fatty liver disease, NAFLD) and the significance of some risk factors, such as obesity and glucose metabolism impairment, for two major ethnic groups of Kuwait: Arabs and South Asians. Subjects and Methods: 143 adults (Arab: $n=81$; South Asian: $n=62$ ) were enrolled in the study. Anthropometric measurements including body mass index (BMI), waist circumference (WC), hip circumference $(\mathrm{HC})$ and waist-to-hip ratio were performed along with abdominal ultrasonography. The prevalence of liver steatosis was assessed; its relation to glucose metabolism impairment, obesity, age and gender was compared in the two ethnic groups. Results: Except for waist-to-hip ratio, the anthropometric parameters were higher in Arabs than South Asians. The respective parameters in Arabs and South Asians were: BMI: $30.9 \pm 6.6$ versus $27.0 \pm 4.5, \mathrm{p}<0.001$; WC: 101.5 \pm 16.4 versus $94.0 \pm 12.2, \mathrm{p}=0.002$; HC: $106.6 \pm 12.4$ versus $99.2 \pm 9.9, p<0.001$. Although Arabs were more obese, they did not exhibit a higher prevalence of steatosis (33.3 vs. $29.0 \%, p=0.583$ ). According to multivariate analysis, only
\end{abstract}

gender (odds ratio 3.93, $\mathrm{p}=0.005$ ), glucose metabolism impairment (odds ratio 4.94, $p=0.003$ ) and WC (odds ratio 4.75, $\mathrm{p}=0.012$ ) remained significantly associated with steatosis. Conclusion: No significant difference in NAFLD prevalence was found between Arabs and South Asians. Only gender, history of impaired glucose metabolism and abdominal obesity expressed by WC had an independent predictive value for developing liver steatosis.

Copyright $\odot 2011$ S. Karger AG, Basel

\section{Introduction}

Liver steatosis is a common reaction of the liver to a variety of noxious stimuli and metabolic disturbances [1]. Nonalcoholic fatty liver disease (NAFLD) is a very frequent form of chronic liver disease. Insulin resistance is recognized as a key promoter of NAFLD, reflected by any kind of glucose metabolism derailment - either type 2 diabetes, or any type of 'prediabetes' [2-9]. According to the published data, the strongest association of NAFLD is with central, not overall obesity $[8,10]$, with intense links to metabolic syndrome. The pandemic of obesity appears to be a global problem, potentially leading from simple steatosis to necroinflammation and finally cirrhosis [2-7]. Patients with nonalcoholic steatohepatitis are at

\section{KARGER}

Fax +4161306 1234

E-Mail karger@karger.ch

www.karger.com
(C) 2011 S. Karger AG, Basel

1011-7571/12/0211-0056\$38.00/0

Accessible online at:

www.karger.com/mpp
Dr. Pavel Babusik, $\mathrm{PhD}$

Namestie S. Moysesa 2A

SK-97401 Banska Bystrica (Slovakia)

Tel. +421 455201540, E-Mail paba54@ hotmail.com 
Table 1. Characteristics and anthropometric measurements of the two ethnic groups

\begin{tabular}{|c|c|c|c|c|}
\hline Variable & $\operatorname{Arabs}(\mathrm{n}=81)$ & Asians $(\mathrm{n}=62)$ & All $(n=143)$ & $\mathrm{p}$ value \\
\hline Gender & & & & $0.140^{\mathrm{a}}$ \\
\hline Male & $28(34.6)$ & $29(46.8)$ & $57(39.9)$ & \\
\hline Female & $53(65.4)$ & $33(53.2)$ & $86(60.1)$ & \\
\hline Diabetes & & & & $0.295^{\mathrm{a}}$ \\
\hline Yes & $15(18.5)$ & $16(25.8)$ & $31(21.7)$ & \\
\hline No & $66(81.5)$ & $46(74.2)$ & $112(78.3)$ & \\
\hline Steatosis & & & & $0.583^{\mathrm{a}}$ \\
\hline Yes & $27(33.3)$ & $18(29.0)$ & $45(31.5)$ & \\
\hline No & $54(66.7)$ & $44(71.0)$ & $98(68.5)$ & \\
\hline Age, years & $37.9 \pm 12.7$ & $40.0 \pm 10.2$ & $38.8 \pm 11.7$ & $0.301^{\mathrm{b}}$ \\
\hline $\mathrm{BMI}, \mathrm{kg} / \mathrm{m}^{2}$ & $30.9 \pm 6.6$ & $27.0 \pm 4.5$ & $29.2 \pm 6.1$ & $<0.001^{b}$ \\
\hline $\mathrm{WC}, \mathrm{cm}$ & $101.5 \pm 16.4$ & $94.0 \pm 12.2$ & $98.2 \pm 15.2$ & $0.002^{\mathrm{b}}$ \\
\hline $\mathrm{HC}, \mathrm{cm}$ & $106.6 \pm 12.4$ & $99.2 \pm 9.9$ & $103.4 \pm 12.0$ & $<0.001^{\mathrm{b}}$ \\
\hline WHR & $0.95 \pm 0.08$ & $0.95 \pm 0.06$ & $0.95 \pm 0.07$ & $0.863^{\mathrm{b}}$ \\
\hline
\end{tabular}

Data for gender, diabetes and steatosis shown as number and percent (in parentheses) of patients, for other variables as mean $\pm \mathrm{SD}$. Diabetes included any glucose metabolism derailment.

${ }^{a} \mathrm{p}$ values generated by $\chi^{2}$ test to compare between Arabs and Asians.

${ }^{b} \mathrm{p}$ values generated by Student's t test to compare between Arabs and Asians.

Table 2. Prevalence of steatosis based on characteristics and anthropometric parameters $(\mathrm{n}=123)$

\begin{tabular}{|c|c|c|c|c|c|c|c|}
\hline Variable & $\mathrm{n}(\%)$ & $95 \% \mathrm{CI}$ & $\mathrm{p}$ value & Variable & n (\%) & $95 \% \mathrm{CI}$ & $\mathrm{p}$ value \\
\hline Male & $28(49.1)$ & $35.6-62.7$ & & Tertile 1 & $1(3.2)$ & $0.1-16.7$ & \\
\hline Female & $17(19.8)$ & $12.0-29.8$ & & Tertile 2 & $9(20.0)$ & $9.6-34.6$ & \\
\hline Age, years & & & $0.025^{\mathrm{b}}$ & Tertile 3 & $35(52.2)$ & $39.7-64.6$ & \\
\hline $30-40$ & $16(28.6)$ & $17.3-42.2$ & & Tertile 1 & $8(21.1)$ & $9.6-37.3$ & \\
\hline$>40$ & $22(42.3)$ & $28.7-56.8$ & & Tertile 2 & $10(20.4)$ & $10.2-34.3$ & \\
\hline Ethnicity & & & $0.583^{\mathrm{a}}$ & Tertile 3 & $27(48.2)$ & $34.7-62.0$ & \\
\hline Arab & $27(33.3)$ & $23.2-44.7$ & & WHR & & & $<0.001^{\mathrm{b}}$ \\
\hline Asian & $18(29.0)$ & $18.2-41.9$ & & Tertile 1 & $3(9.1)$ & $1.9-24.3$ & \\
\hline Tertile 1 & $3(8.3)$ & $1.8-22.5$ & & \multirow{3}{*}{\multicolumn{4}{|c|}{$\begin{array}{l}\text { Diabetes included any glucose metabolism derailment. } \\
\text { a } p \text { values generated by } \chi^{2} \text { test. } \\
{ }^{b} \text { p values generated by } \chi^{2} \text { for linear trend. }\end{array}$}} \\
\hline Tertile 2 & $13(28.9)$ & $16.4-44.3$ & & & & & \\
\hline Tertile 3 & $29(46.8)$ & $34.0-59.9$ & & & & & \\
\hline
\end{tabular}


Table 3. Prevalence of steatosis among Arabs and Asians according to their characteristics

\begin{tabular}{|c|c|c|c|c|c|c|}
\hline \multirow[t]{3}{*}{ Variable } & \multicolumn{3}{|c|}{$\operatorname{Arabs}(\mathrm{n}=81)$} & \multicolumn{3}{|c|}{ Asians $(n=62)$} \\
\hline & \multicolumn{2}{|l|}{ steatosis } & \multirow[t]{2}{*}{$\mathrm{p}$ value } & \multicolumn{2}{|l|}{ steatosis } & \multirow[t]{2}{*}{$\mathrm{p}$ value } \\
\hline & $\mathrm{n}(\%)$ & $95 \% \mathrm{CI}$ & & $\mathrm{n}(\%)$ & $95 \% \mathrm{CI}$ & \\
\hline Gender & & & $0.001^{\mathrm{a}}$ & & & $0.045^{\mathrm{a}}$ \\
\hline Male & $16(57.1)$ & $37.2-75.6$ & & $12(41.4)$ & $23.5-61.1$ & \\
\hline Female & $11(20.8)$ & $10.8-34.1$ & & $6(18.2)$ & $7.0-35.5$ & \\
\hline Age, years & & & $0.016^{\mathrm{b}}$ & & & $0.046^{\mathrm{b}}$ \\
\hline$<30$ & $5(21.7)$ & $7.5-43.7$ & & $2(16.7)$ & $2.1-48.4$ & \\
\hline $30-40$ & $8(25.0)$ & $11.5-43.4$ & & $8(33.3)$ & $15.6-55.3$ & \\
\hline Diabetes & & & $0.002^{\mathrm{a}}$ & & & $0.001^{\mathrm{b}}$ \\
\hline Yes & $10(66.7)$ & $38.4-88.2$ & & $10(62.5)$ & $35.4-84.8$ & \\
\hline No & $17(25.8)$ & $15.8-38.0$ & & $8(17.4)$ & $7.8-31.4$ & \\
\hline $\mathrm{BMI}, \mathrm{kg} / \mathrm{m}^{2}$ & & & $<0.001^{\mathrm{b}}$ & & & $0.175^{\mathrm{b}}$ \\
\hline Tertile 1 & $0(0.0)$ & $0.0-21.8$ & & $3(14.3)$ & $3.0-36.3$ & \\
\hline Tertile 2 & $4(18.2)$ & $5.2-40.3$ & & $9(39.1)$ & $19.7-61.5$ & \\
\hline Tertile 3 & $23(52.3)$ & $36.7-67.5$ & & $6(33.3)$ & $13.3-59.0$ & \\
\hline $\mathrm{WC}, \mathrm{cm}$ & & & $<0.001^{\mathrm{b}}$ & & & $0.003^{\mathrm{b}}$ \\
\hline Tertile 1 & $1(6.7)$ & $0.2-31.9$ & & $0(0.0)$ & $0.0-20.6$ & \\
\hline Tertile 2 & $1(4.8)$ & $5.2-40.3$ & & $8(33.3)$ & $15.6-55.3$ & \\
\hline Tertile 3 & $25(55.6)$ & $36.7-67.5$ & & $10(45.5)$ & $24.4-67.8$ & \\
\hline $\mathrm{HC}, \mathrm{cm}$ & & & $0.002^{\mathrm{b}}$ & & & $0.340^{\mathrm{b}}$ \\
\hline Tertile 1 & $3(20.0)$ & $4.3-48.1$ & & $5(21.7)$ & $7.5-43.7$ & \\
\hline Tertile 2 & $3(11.1)$ & $2.4-29.2$ & & $7(31.8)$ & $13.9-54.9$ & \\
\hline Tertile 3 & $21(53.8)$ & $37.2-69.9$ & & $6(35.3)$ & $14.2-61.7$ & \\
\hline WHR & & & $0.004^{\mathrm{b}}$ & & & $0.006^{\mathrm{b}}$ \\
\hline Tertile 1 & $2(10.0)$ & $1.2-31.7$ & & $1(7.7)$ & $0.2-36.0$ & \\
\hline Tertile 2 & $4(26.7)$ & $7.8-55.1$ & & $4(19.0)$ & $5.4-41.9$ & \\
\hline Tertile 3 & $21(45.7)$ & $30.9-61.0$ & & $13(46.4)$ & $27.5-66.1$ & \\
\hline
\end{tabular}

increased risk of premature death compared to the general population [11]. In our previous study [12], we showed that the two main ethnic groups in Kuwait differed in the degree and the type of obesity and its impact on some metabolic risk factors of atherosclerosis. Therefore, the aim of this study was to clarify the significance of the differences for the prevalence of NAFLD.

\section{Subjects and Methods}

The study was conducted from January 2007 to September 2008. 143 adult subjects, patients and clients of the Medical Clinic in Al Rashid Hospital, Kuwait were examined (Arabs: $\mathrm{n}=81$, South Asians: $n=62$; age range: $18-64$ years). The Arabs were from Kuwait, Saudi Arabia, United Arab Emirates, Jordan, Egypt and Syria. The South Asians were from India, Pakistan, Bangladesh or Sri Lanka. Ethnicity was established based on official documents showing country of origin and the person's own confirmation of the data. Exclusion criteria were: presence of chronic liver disease other than NAFLD, chronic wasting conditions, diabetes type 1 , history of jejunoileal bypass surgery, alcohol and/or substance abuse, chronic medication with potential hepatotoxicity, pregnancy, and conditions with fluid retention. Basic anthropometric measurements were done by a qualified and properly trained nurse. A nonstretchable tape was used for measurements of circumferences while the persons were in an upright position. The waist circumference (WC) was taken in the middle between the rib cage and the pelvis as the shortest circumference. The hip circumference (HC) was measured as the largest circumference at the level of greater trochanters. Body weight was checked by an electronic scale and the height was measured by a measuring rod 
Table 4. Comparison of anthropometric measures according to steatosis (mean $\pm \mathrm{SD}$ )

\begin{tabular}{|c|c|c|c|}
\hline \multirow[t]{2}{*}{ Variable } & \multicolumn{2}{|l|}{ Steatosis } & \multirow[t]{2}{*}{$\mathrm{p}$ value } \\
\hline & yes $(n=45)$ & no $(\mathrm{n}=98)$ & \\
\hline \multicolumn{4}{|l|}{ Arabs } \\
\hline Age, years & $43.6 \pm 13.5$ & $35.1 \pm 11.4$ & 0.004 \\
\hline BMI, kg/m² & $34.9 \pm 5.9$ & $28.9 \pm 6.1$ & $<0.001$ \\
\hline $\mathrm{WC}, \mathrm{cm}$ & $111.8 \pm 15.9$ & $96.3 \pm 14.2$ & $<0.001$ \\
\hline $\mathrm{HC}, \mathrm{cm}$ & $112.9 \pm 13.0$ & $103.5 \pm 11.0$ & 0.001 \\
\hline WHR & $0.99 \pm 0.07$ & $0.93 \pm 0.07$ & 0.001 \\
\hline \multicolumn{4}{|l|}{ Asians } \\
\hline Age, years & $44.0 \pm 12.0$ & $38.3 \pm 9.0$ & 0.046 \\
\hline BMI, kg/m² & $28.7 \pm 4.4$ & $26.3 \pm 4.4$ & 0.054 \\
\hline $\mathrm{WC}, \mathrm{cm}$ & $99.7 \pm 10.1$ & $91.7 \pm 12.3$ & 0.017 \\
\hline $\mathrm{HC}, \mathrm{cm}$ & $102.2 \pm 10.7$ & $97.9 \pm 9.4$ & 0.126 \\
\hline WHR & $0.98 \pm 0.05$ & $0.93 \pm 0.06$ & 0.013 \\
\hline \multicolumn{4}{|l|}{ All } \\
\hline Age, years & $43.8 \pm 12.8$ & $36.5 \pm 10.5$ & 0.001 \\
\hline BMI, $\mathrm{kg} / \mathrm{m}^{2}$ & $32.4 \pm 6.1$ & $27.7 \pm 5.6$ & $<0.001$ \\
\hline $\mathrm{WC}, \mathrm{cm}$ & $107.0 \pm 15.0$ & $94.2 \pm 13.5$ & $<0.001$ \\
\hline $\mathrm{HC}, \mathrm{cm}$ & $108.6 \pm 13.1$ & $101.0 \pm 10.6$ & 0.001 \\
\hline WHR & $0.98 \pm 0.06$ & $0.93 \pm 0.07$ & $<0.001$ \\
\hline
\end{tabular}

p values are generated by Student's t test.

attached to the same scale. Ultrasound examination of the upper abdomen was performed by a consultant radiologist skilled in the method and blind to the exact purpose of the examination. The criteria for steatosis were: increased parenchymal echogenicity of the liver compared to the kidney, vascular blurring, and deep attenuation of the ultrasound beam. Patients were either directly tested, or questioned regarding their previous history of diabetes, taking into account any derailment in glucose metabolism related to type 2 diabetes, including both impaired glucose tolerance and impaired fasting blood glucose.

\section{Statistical Methods}

All statistical analyses were performed using STATA (SE 8.2, StataCorp, College Station, Tex., USA). A $p<0.05$ was used as the threshold for statistical significance. The $\chi^{2}$ test, $\chi^{2}$ test for linear trend or Fisher's exact test were used to assess the association between two qualitative variables wherever appropriate. The 95\% confidence intervals (CI) for the prevalence of steatosis were calculated using binomial distribution. Quantitative variables were compared between steatosis and nonsteatosis groups using an independent samples t test. Unadjusted odds ratios and their $95 \%$ CI were calculated separately for different risk factors in the prevalence of steatosis. Multiple logistic regression was used to estimate the risk of these factors in the prevalence of steatosis after controlling for confounding among them. The adjusted odds ratios and their 95\% CI for associated factors were computed from the coefficients of the logistic regression model.

Nonalcoholic Liver Steatosis

\section{Results}

The parameters studied and characteristics of the two ethnic groups are shown in table 1. Previous history of glucose metabolism impairment, prevalence of steatosis and age were similar in both groups. Mean values of body mass index (BMI), WC, and $\mathrm{HC}$ were higher in Arabs than South Asians and the differences were statistically significant: BMI: $30.9 \pm 6.6$ versus $27.0 \pm 4.5, \mathrm{p}<0.001$; WC: $101.5 \pm 16.4$ versus $94.0 \pm 12.2, \mathrm{p}=0.002$; and HC $106.6 \pm 12.4$ versus $99.2 \pm 9.9, \mathrm{p}<0.001$. The waist-tohip ratio (WHR) was similar in Arabs (0.95 \pm 0.08$)$ and South Asians $(0.95 \pm 0.06)$; the difference was not statistically significant $(\mathrm{p}=0.863)$.

The prevalence of steatosis according to characteristics and anthropometric parameters is shown in table 2. Gender was highly predictive for the incidence of steatosis: the incidence was male: $49.1 \%$; female: $19.8 \%$. The difference was statistically significant $(p<0.001)$. There was no difference among the two ethnic groups in incidence rate: Arabs 33.3\% and South Asians 29.0\% ( $\mathrm{p}=0.683$ ). Age was a predictor of incidence of steatosis, showing a linear trend $(\mathrm{p}=0.025)$. We found highly significant as- 
Table 5. Risk factors associated with steatosis by logistic regression analyses among the studied sample

\begin{tabular}{|c|c|c|c|c|c|c|}
\hline \multirow[t]{2}{*}{ Variable } & \multicolumn{3}{|c|}{ Univariate analysis } & \multicolumn{3}{|c|}{ Multivariate analysis } \\
\hline & $\begin{array}{l}\text { crude } \\
\text { odds ratio }\end{array}$ & $95 \% \mathrm{CI}$ & $\mathrm{p}$ value & $\begin{array}{l}\text { adjusted } \\
\text { odds ratio }\end{array}$ & $95 \% \mathrm{CI}$ & $\mathrm{p}$ value \\
\hline \multicolumn{7}{|l|}{ Gender } \\
\hline Female & 1.00 & & & 1.00 & & \\
\hline Male & 3.92 & $1.86-8.23$ & $<0.001$ & 3.93 & $1.53-10.10$ & 0.005 \\
\hline \multicolumn{7}{|l|}{ Age, years } \\
\hline$<30$ & 1.00 & & & 1.00 & & \\
\hline $30-40$ & 1.60 & $0.58-4.40$ & 0.362 & 0.86 & $0.25-2.92$ & 0.804 \\
\hline$>40$ & 2.93 & $1.09-7.93$ & 0.034 & 1.21 & $0.33-4.40$ & 0.773 \\
\hline \multicolumn{7}{|l|}{ Ethnicity } \\
\hline Arab & 1.00 & & & 1.00 & & \\
\hline \multicolumn{7}{|l|}{ Diabetes } \\
\hline No & 1.00 & & & 1.00 & & \\
\hline Yes & 6.33 & $2.68-14.95$ & $<0.001$ & 4.94 & $1.71-14.24$ & 0.003 \\
\hline \multicolumn{7}{|l|}{ BMI, kg/m² } \\
\hline Tertile 1 and 2 & 1.00 & & & 1.00 & & \\
\hline Tertile 3 & 3.57 & $1.70-7.49$ & 0.001 & 1.26 & $0.39-4.13$ & 0.699 \\
\hline \multicolumn{7}{|l|}{$\mathrm{WC}, \mathrm{cm}$} \\
\hline Tertile 1 and 2 & 1.00 & & & 1.00 & & \\
\hline Tertile 3 & 7.22 & $3.18-16.39$ & $<0.001$ & 4.75 & $1.40-16.11$ & 0.012 \\
\hline \multicolumn{7}{|l|}{ WHR } \\
\hline Tertile 1 and 2 & 1.00 & & & 1.00 & & \\
\hline Tertile 3 & 4.48 & $2.03-9.88$ & $<0.001$ & 1.48 & $0.51-4.32$ & 0.474 \\
\hline
\end{tabular}

sociations between the presence of glucose metabolism impairment and steatosis (64.5\% steatosis among diabetics vs. $22.3 \%$ in nondiabetics, $p<0.001$ ), and all anthropometric measures of obesity (expressed as linear trends between tertiles with $\mathrm{p}<0.001$ for BMI, WC and WHR, and $\mathrm{p}=0.003$ for $\mathrm{HC}$ ) and steatosis as well.

The prevalence of steatosis among Arabs and Asians based on their characteristics and the anthropometric measurements is shown in table 3. In Arabs, gender ( $\mathrm{p}=$ $0.001)$, history of diabetes $(\mathrm{p}=0.02)$ and all measures of obesity were significantly associated with steatosis $(\mathrm{p}=$ 0.001 for BMI and WC, $p=0.002$ for HC and $p=0.004$ for WHR). In South Asians, gender ( $p=0.045)$, history of glucose metabolism impairment $(\mathrm{p}=0.001), \mathrm{WC}(\mathrm{p}=$ $0.003)$ and WHR $(\mathrm{p}=0.006)$ were significantly associated with steatosis. In both ethnic groups age was associated with steatosis $(\mathrm{p}=0.016$ and $\mathrm{p}=0.046$ for Arabs and South Asians, respectively).

The comparison of anthropometric measures in relation to steatosis is shown in table 4. Among Arabs, steato- sis was associated with higher age (43.6 \pm 13.5 years for steatosis vs. $35.1 \pm 11.4$ years without steatosis, $\mathrm{p}=0.004)$, higher values of BMI $(34.9 \pm 5.9$ vs. $28.9 \pm 6.1, \mathrm{p}<$ $0.001)$, WC $(111.8 \pm 15.9$ vs. $96.3 \pm 14.2, \mathrm{p}<0.001)$, HC (112.9 \pm 13.0 vs. $103.5 \pm 11.0, \mathrm{p}=0.001)$ and WHR (0.99 \pm 0.07 vs. $0.93 \pm 0.07, \mathrm{p}=0.001$ ). These associations were statistically highly significant. Among South Asians, associations existed between steatosis and age (44.0 \pm 12.0 vs. $38.3 \pm 9.0, p=0.046$ for steatosis and nonsteatosis subgroup, respectively), WC (99.7 \pm 10.1 vs. $91.7 \pm$ $12.3, p=0.017)$ and WHR $(0.98 \pm 0.05$ vs. $0.93 \pm 0.06$, $\mathrm{p}=0.013)$. Overall, age was significantly related to steatosis $(43.8 \pm 12.8$ vs. $36.5 \pm 10.5, \mathrm{p}=0.001)$ for the entire group studied. Significant correlations were present between steatosis and BMI, WC, WHR $(\mathrm{p}<0.001)$ and HC $(\mathrm{p}=0.001)$ as well.

Risk factors associated with steatosis by logistic regression analyses are given in table 5. After multivariate analysis only gender (odds ratio 3.93, $\mathrm{p}=0.005$ ), history of glucose metabolism impairment (odds ratio 4.94, $\mathrm{p}=$ 
0.003 ) and WC (odds ratio 4.75, $\mathrm{p}=0.012$ ) remained statistically significantly associated with steatosis. No statistical significance was found between steatosis and age, ethnicity, BMI or WHR.

\section{Discussion}

In our study, abdominal type obesity, defined through WC, was confirmed to be linked with steatosis in both ethnic groups, after adjustment for all other variables. Along with this association, we observed statistically significant differences between the two studied ethnicities: Arabs were more obese than South Asians based on BMI, $\mathrm{WC}$ and HC. In spite of that, the prevalence of glucose metabolism impairment and occurrence of steatosis in the two groups were similar. This finding is similar to the results of our former study [12]: the same degree of obesity had more deleterious metabolic effects in South Asians than Arabs in Kuwait. Previous studies, too, confirmed that the South Asian ethnicity carries a higher genuine risk to exhibit adverse effects of obesity, in comparison with other ethnic groups, namely the Caucasians [13]. The overall prevalence of liver steatosis in our study was $31.5 \%$. We found a very strong correlation between steatosis and a history of glucose metabolism impairment. This confirms the fact that insulin resistance is a main risk factor for developing NAFLD [2-9, 14]. The prevalence of NAFLD is not equal in different ethnicities [15-21]. The information about the different impact of obesity on developing NAFLD between Arabs and South Asians was lacking to date. We found some differences between our two studied ethnic groups: in Arabs, all studied anthropometric parameters were predictors of liver steatosis, contrary to the South Asians, where only
WC and WHR were predictors of steatosis. In a multivariate analysis, however, WC remained the only anthropometric parameter related to steatosis, along with male gender and a history of impaired glucose metabolism. After adjustment for all other variables, the risk of steatosis for males was 4 times higher than for females. It is possible to speculate to what extent the differences were a result of specific lifestyle habits, with daily activities shifted to the late night hours (main meal consumed late at night), along with specific dietary habits both of which could lead to multiple metabolic impairment [22].

\section{Conclusion}

Our study confirmed that the prevalence of NAFLD is quite high in two major ethnic groups in Kuwait: Arabs and South Asians, and despite Arabs being more obese, the prevalence of steatosis did not differ from South Asians. The history of impaired glucose metabolism was a strong link to NAFLD. WC was an independent predictor of NAFLD in both ethnic groups, and NAFLD was much more common in the male population of Kuwait. The main limitation of our study is the small sample size and to some extent, the selective segment of the Kuwait population studied. Despite this, some careful extrapolations are possible to be done towards the whole Arab and South Asian population in Kuwait.

\section{Acknowledgment}

The authors wish to thank Ms. Jacinta F. Martiz for her technical help.

\section{References}

1 Bacon BR: Genetic, metabolic, and infiltrative diseases affecting the liver; in Fauci AS, Braunwald E, Kasper DL, Hauser SL, Longo DL, Jameson JL, Loscalzo J (eds): Harrison's Principles of Internal Medicine, ed 17. New York, McGraw-Hill, 2008, pp 1980-1983.

-2 Marceau P, Biron S, Hould F-S, Marceau S, Simard S, Thung SN, Kral JG: Liver pathology and the metabolic syndrome $\mathrm{X}$ in severe obesity. J Clin Endocrinol Metab 1999;84: 1513-1517.
- 3 Dixon JB, Bhathal PS, O’Brien PE: Nonalcoholic fatty liver disease: predictors of nonalcoholic steatohepatitis and liver fibrosis in the severely obese. Gastroenterology 2001; 121:91-100.

$\checkmark 4$ Garcia-Monzon C, Martin-Perez E, Iacono OL, Fernandez-Bermejo M, Majano PL, Apolinario A, Larranaga E, Moreno-Otero $\mathrm{R}$ : Characterization of pathogenic and prognostic factors of nonalcoholic steatohepatitis associated with obesity. J Hepatol 2000;33: 716-724.
5 Musso G, Gambino R, De Michieli F, Cassader M, Rizzeto M, Durazzo M, Faga E, Silli B, Pagano G: Dietary habits and their relations to insulin resistance and postprandial lipemia in nonalcoholic steatohepatitis. Hepatology 2003;37:909-916.

-6 Solga S, Alkhuraishe AR, Clark JM, Torbenson, M, Greenwald A, Diehl AM, Magnuson T: Dietary composition and nonalcoholic fatty liver disease. Dig Dis Sci 2004;49:15781583. 
7 Lewis GF, Carpentier A, Adeli K, Giacca A: Disordered fat storage and mobilization in the pathogenesis of insulin resistance and type 2 diabetes. Endocr Rev 2002;23:201229.

$>8$ Park SH, Kim BI, Kim SH, Kim HJ, Park DI, Cho YK, Sung IK, Sohn CI, Kim H, Keum DK, Kim HD, Park JH, Kang JH, Jeon WK: Body fat distribution and insulin resistance: beyond obesity in non-alcoholic fatty liver disease among obese men. J Am Coll Nutr 2007;26:321-326.

$\checkmark 9$ Yun JW, Cho YK, Park JH, Kim JH, Park DI Sohn CI, Jeon WK, Kim BI: Abnormal glucose tolerance in young male patients with nonalcoholic fatty liver disease. Liver Int 2009;29:525-529.

10 Kral JG, Schaffner F, Pierson RN Jr, Wang J: Body fat topography as an independent predictor of fatty liver. Metabolism 1993;42: 548-551.

-11 Söderberg C, Stål P, Askling J, Glaumann H, Lindberg G, Marmur J, Hultcrantz R: Decreased survival of subjects with elevated liver function tests during a 28-year follow-up. Hepatology 2009;51:595-602.

12 Babusik P, Duris I: Comparison of obesity and its relationship to some metabolic risk factors of atherosclerosis in Arabs and South Asians in Kuwait. Med Princ Pract 2010;19: 275-280.
13 Lear SA, Toma M, Birmingham CL, Frolich JJ: Modification of the relationship between simple anthropometric indices and risk factors by ethnic background. Metabolism 2003;52:1295-1301.

14 Chitturi S, Abeygunasekera S, Farrel GC, Holmes-Walker J, Hui JM, Fung C, Karim R, Lin R, Sanarasinghe D, Liddle C, Weltman $\mathrm{M}$, George J: NASH and insulin resistance: insulin hypersecretion and specific association with the insulin resistance syndrome. Hepatology 2002;35:367-372.

15 Omagari K, Kadokawa Y, Masuda J, Egawa I, Sawa T, Hazama $\mathrm{H}$, Ohba $\mathrm{K}$, Isomoto $\mathrm{H}$, Mizuta Y, Hayashida K, Murase K, Kadota T, Murata I, Kohno S: Fatty liver in non-alcoholic non-overweight Japanese adults: incidence and clinical characteristics. J Gastroenterol Hepatol 2002;17:1089-1105.

16 Bellentani S, Saccoccio G, Massutti F, Crose LS, Brandi G, Sasso F, Cristanini G, Tiribelli C: Prevalence of and risk factors for hepatic steatosis in Northern Italy. Ann Intern Med 2000;132:112-117.
17 Jimba S, NakagamiT, Takahashi M, Wakamatsu T, Hirota Y, Ywamoto Y, Wasada T: Prevalence of non-alcoholic fatty liver disease and its association with impaired glucose metabolism in Japanese adults. Diabet Med 2005;22:1141-1145.

18 Nomura H, Kashiwagi S, Hayashi J, Kajiyama W, Tani S, Goto M: Prevalence of fatty liver in a general population of Okinawa, Japan. Jpn J Med 1988;27:142-149.

19 Browning JD, Szczepaniak LS, Dobbins R, Nuremberg P, Horton JD, Cohen JC, Grundy SM, Hobbs HH: Prevalence of hepatic steatosis in an urban population in the United States: impact of ethnicity. Hepatology 2004; 40:1387-1395.

20 Chitturi S, Farrell GC, Hashimoto E, Saibara T, Lau GKK, Sollano JD: Non-alcoholic fatty liver disease in the Asia-Pacific region: definitions and overview of proposed guidelines. J Gastroenterol Hepatol 2007;22:778-787.

21 Caldwell SH, Harris DM, Patrie JT, Hespenheide EE: Is NASH underdiagnosed among African Americans? Am J Gastroenterol 2002;97:1496-1500.

-22 Kreier F, Yilmaz A, Kalsbeek A, Romijn JA, Sauerwein HP, Fliers E, Buijs RM: Hypothesis: shifting the equilibrium from activity to food leads to autonomic unbalance and the metabolic syndrome. Diabetes 2003;52: 2652-2656. 